\begin{tabular}{|l|l|}
\hline DOI & $10.1007 / \mathrm{s} 00393-013-1240-8$ \\
\hline Copyright & Springer-Verlag Berlin Heidelberg - 2013 \\
\hline
\end{tabular}

\title{
Originalien
}

\section{Treatment of ankylosing spondylitis with biologics and targeted physical therapy}

\section{Positive effect on chest pain, diminished chest mobility, and respiratory function}

\author{
Z. Gyurcsik ${ }^{1} \cdot$ N. Bodnár ${ }^{2} \cdot$ Z. Szekanecz ${ }^{2} \cdot$ S. Szántó \\ ${ }^{1}$ Department of Physiotherapy, University of Debrecen Medical and Health Sciences Center, \\ Debrecen, Hungary \\ ${ }^{2}$ Department of Rheumatology, Institute of Medicine, University of Debrecen Medical and Health \\ Science Center, Debrecen, Hungary
}

\section{Corresponding affiliation}

Prof. Z. Szekanecz M.D., Ph.D., D.Sc.

Department of Rheumatology, Institute of Medicine, University of Debrecen Medical and Health Science Center

98 Nagyerdei Str.

4012 Debrecen

Hungary

szekanecz.zoltan@med.unideb.hu

\section{Abstract}

Objective Biologics are highly effective in ankylosing spondylitis (AS). In this selfcontrolled study, we assessed the additive value of complex physiotherapy in decreasing chest 
pain and tenderness and improving respiratory function in AS patients treated with tumor necrosis factor $\alpha$ (TNF- $\alpha$ ) inhibitors.

Patients and methods The trial consisted of 2 parts. In study I, clinical data of AS patients with ( $\mathrm{n}=55)$ or without biological therapy $(\mathrm{n}=20)$ were retrospectively analyzed and compared. Anthropometrical data, duration since diagnosis and patient assessment of disease activity, pain intensity, tender points, sacroiliac joint involvement determined by X-ray, functional condition, and physical activity level were recorded. Subjective, functional, and physical tests were performed. In study II, 10 voluntary patients ( 6 men and 4 women, age $52.4 \pm 13.6$ years) with definite AS and receiving anti-TNF therapy were recruited. It was a prospective, non-randomized physiotherapeutic trial. BASFI (Bath Ankylosing Spondylitis Functional Index), BASDAI (Bath Ankylosing Spondylitis Disease Activity Index), modified Schober Index, occiput-to-wall distance, and fingertip-to-floor distance were evaluated. Forced vital capacity, forced 1-s expiratory volume, peak expiratory flow, and maximum voluntary ventilation were recorded. Furthermore, typical tender points were recorded. A targeted physiotherapy program was conducted twice a week for 12 weeks and all above parameters were recorded at baseline and after 12 weeks.

Results Differences in patient assessment of disease activity $(p=0.019)$ and pain intensity $(p=0.017)$ were found in study I. Pain and tenderness of the thoracic spine were observed in both groups. Back pain without biologic therapy was slightly higher than other group. In study II, we found that patient assessment of disease activity and pain intensity significantly improved after the physical therapy program $(p=0.002$ and $p<0.001)$. BASFI and BASDAI increased after treatment $(\mathrm{p}=0.004$ and $\mathrm{p}<0.001)$. The finger-to-floor distance, chest expansion, and modified Schober index increased $(p=0.008, p<0.001$, and $\mathrm{p}=0.031$, respectively). The respiratory functional parameters showed a tendency towards improvement.

Conclusion AS patients already receiving biological therapy may benefit from additional targeted physiotherapy. Physical therapy may be of important additive value in AS patients being treated with biological. The exercise program presented here showed an improvement in functional parameters as well as spine and chest mobility, thereby enhancing the favorable effects of biological therapy.

\section{Keywords}


Breathing exercises $\cdot$ Physiotherapy $\cdot$ Biological therapy $\cdot$ Anti-TNF therapy $\cdot$ Respiration

\section{Behandlung der ankylosierenden Spondylitis mit Biologika und gezielter Physiotherapie}

\section{Positive Wirkung auf Thoraxschmerz, verminderte Thoraxbeweglichkeit und} Atemfunktion

\section{Zusammenfassung}

Ziel Biologika sind hochwirksam bei ankylosierender Spondylitis (AS). In dieser eigenkontrollierten Studie wurde der Mehrwert einer komplexen Physiotherapie zur Linderung von Thoraxschmerzen und -empfindlichkeit sowie zur Verbesserung der Atemfunktion bei AS-Patienten untersucht, welche mit Tumornekrosefaktor-alpha(TNF- $\alpha$ )Inhibitoren behandelt wurden.

Patienten und Methoden Die Studie bestand aus 2 Teilen. In Studie I wurden die klinischen Daten von AS-Patienten mit $(n=55)$ oder ohne $(n=20)$ biologische Therapie retrospektiv ausgewertet und verglichen. Anthropometrische Daten, Zeit seit Diagnose und Patientenbeurteilung der Krankheitsaktivität, Schmerzintensität, Druckpunkte, Beteiligung des Sakroiliakalgelenks gemäß Röntgenbild, Funktionszustand und körperliches Aktivitätsniveau wurden dokumentiert. Es wurden subjektive, funktionelle und körperliche Tests durchgeführt. In Studie II wurden 10 freiwillig teilnehmende Patienten (6 Männer, 4 Frauen, Alter: 52,4 $\pm 13,6$ Jahre) mit gesicherter AS und unter Anti-TNF-Therapie aufgenommen. Es handelte sich um eine prospektive nichtrandomisierte physiotherapeutische Studie. BASFI (Bath Ankylosing Spondylitis Functional Index), BASDAI (Bath Ankylosing Spondylitis Disease Activity Index), modifizierter Schober-Index, Hinterkopf-Wand-Abstand und Finger-Boden-Abstand wurden untersucht. Auch die forcierte Vitalkapazität, das forcierte expiratorische 1-s-Volumen, der expiratorische Spitzenfluss und die maximale willkürliche Ventilation wurden dokumentiert. Außerdem wurden typische Druckpunkte aufgezeichnet. Ein gezieltes Physiotherapieprogramm wurde 2-mal pro Woche durchgeführt und sämtliche genannten Parameter zu Beginn der Studie und nach 12 Wochen dokumentiert.

Results In Studie I stellten sich Unterschiede bei der Patientenbeurteilung der Krankheitsaktivität $(p=0,019)$ und Schmerzintensität $(p=0,017)$ heraus. Schmerz und Empfindlichkeit der Brustwirbelsäule wurden in beiden Gruppen beobachtet. 
Rückenschmerzen ohne biologische Therapie waren etwas stärker als in der anderen Gruppe.

In Studie II stellte sich heraus, dass die Patientenbeurteilung der Krankheitsaktivität und Schmerzintensität sich signifikant nach dem Physiotherapieprogramm besserte ( $p=0,002$ bzw. $p<0,001)$. BASFI und BASDAI stiegen nach Behandlung an ( $p=0,004$ bzw. $p<0,001)$. Der Finger-Boden-Abstand, die Thoraxausdehnung und der modifizierte Schober-Index nahmen $\mathrm{zu}(\mathrm{p}=0,008 ; \mathrm{p}<0,001$ bzw. $\mathrm{p}=0,031)$. Die funktionellen Atemparameter wiesen eine Tendenz in Richtung der Verbesserung auf.

Schlussfolgerung AS-Patienten, die bereits eine biologische Therapie erhalten, ziehen möglicherweise einen Nutzen aus zusätzlicher gezielter Physiotherapie. Für AS-Patienten unter Biologikatherapie kann die Physiotherapie einen bedeutenden zusätzlichen Wert darstellen. Das hier vorgestellte Trainingsprogramm führte zu Besserung funktioneller Parameter sowie der Wirbelsäulen- und Thoraxbeweglichkeit, somit konnten die günstigen Wirkungen der biologischen Therapie verstärkt werden.

\section{Schlüsselwörter}

Atemübungen $\cdot$ Physiotherapie $\cdot$ Biologische Therapie $\cdot$ Anti-TNF-Therapie $\cdot$ Atmung

\section{Introduction}

Ankylosing spondylitis (AS) is a chronic inflammatory disease involving entheses and joints around the spine. The most widespread involvement of the respiratory system occurs when this pathological process gives rise to chest pain with kyphosis and decreased chest expansion. During healing of the inflammatory process, calcification occurs, leading to rigidity with a consequent decrease of chest expansion — which is exacerbated by the kyphotic spinal structure and intercostal muscles inefficiency - and changed respiratory function $[\underline{1}, \underline{2}, \underline{3}, \underline{4}]$.

Patients with chest pain and without accompanying respiratory symptoms (dyspnea or cough), suffer from primary musculoskeletal involvement. With subsequent involvement of the thoracic spine and occurrence of enthesopathy at the costosternal and manubriosternal joints, patients may experience chest pain when coughing or sneezing $[\underline{5}, \underline{6}, \underline{7}]$. 
Since mostly the structural changes of the chest wall trigger chest pain, the cause can be obviously detected by palpation, localized swelling, and tender points. Some of the characteristic trigger points include the upper trapezius, sternocostal and costochondral junction, manubriosternal junction, the vertebral spinous processes, and the xiphoid process [8]. For AS patients, active disease means pain, mobility restriction, muscle tension, inability to stay supine, restriction in chest mobility, dyspnea, disturbed sleep, and difficulty to breathe $[\underline{6}, \underline{9}]$.

Progressive ankylosis of the thoracic spine in AS will eventually lead to restrictive pulmonary function impairment, characterized by reduced vital capacity (VC), increased ratio of forced 1-s expiratory volume (FEV1) and forced vital capacity (FVC). Respiratory function in AS shows a typical restrictive pattern, which is characterized by decrease of FVC $<80 \%$ and FEV1 with normal FEV1/FVC ratio $[\underline{1}, \underline{7}, \underline{10}]$.

Both pharmacological treatment with primarily tumor necrosis factor- $\alpha$ (TNF- $\alpha)$ inhibitors and complex physical exercise are effective and important [11, 12, 13]. Anti-TNF agents are particularly effective during the early, inflammatory stages of the disease $[\underline{4}, \underline{11}]$. Biologics are able to decrease inflammatory pain and muscle stiffness, and improve functional capacity, mobility and quality of life [11]. Physical therapy may have additive value by maintaining or even improving mobility, fitness, and general health. It also plays an important role in the prevention and management of the deformities related to AS [1ㄹ, 14].

In our previous study we analyzed $75 \mathrm{AS}$ patients from the point of view of gender differences and they did not show obvious variances [15]. Therefore in the current study (I), we retrospectively examined the same patients being on the basis therapy whether there are differences of physical and certain functional parameters between patient with or without biological therapy, and (II) prospectively, in a small, volunteer group of AS patients treated with biological we assessed the effects of a targeted physical therapy program on chest pain, tenderness, mobility, and respiratory function. It was hypothesized that AS patients receiving biological therapy may have further benefit from a targeted physical therapy program.

\section{Patients and methods}

\section{Study design and patients}

Study 1 (retrospective analysis) Clinical data of AS patients with biological therapy $(n=55)$ or without biological therapy $(n=20)$ were retrospectively analyzed and compared at the 
Department of Rheumatology, Medical and Health Sciences Center, University of Debrecen. All patients had definite AS according to the modified New York criteria [16]. Informed consent was obtained from all participants. Anthropometrical data, time since diagnosis and patient assessment of disease activity, functional capacity, BASDAI (Bath Ankylosing Spondylitis Disease Activity Index) and BASFI (Bath Ankylosing Spondylitis Functional Index), pain intensity on a VAS (visual analog scale), drugs history, sacroiliitis stage assessed by X-ray, and levels of physical activity were recorded. Functional and physical tests were performed by the same physician as described below. None of the patients had a history of cardiopulmonary diseases.

Study II (prospective, self-coontrolled analysis) Of the 55 AS patients with biological therapy described above, 10 volunteered for this study ( 6 men with age of $55.2 \pm 13.32$ years and 4 women with age of $48.25 \pm 14.97$ years). This part was based on a prospective, nonrandomized physiotherapeutic intervention, including a targeted physical therapy program. The participation was voluntary. All 55 patients of study I were contacted by mail, which had been sent twice. A total of 17 patients were interested in the program, but because of familial and logistical reasons, only 10 patients could complete the study. Informed consent was obtained from all participants. Age, height, weight, disease duration, drug history, radiological stage, and physical activity level were recorded.

The physical examinations were performed by the same physician (N.B.) before and after the targeted therapy program. All patients had recent respiratory function tests and these were repeated. None of the patients had any overt cardiopulmonary diseases.

\section{Biological therapy}

All patients with biological therapy (study I and II) had received etanercept or infliximab according to standard of care for at least 3 months prior to the study [11].

\section{Physical therapy}

The physical therapy program included conventional exercise, global posture reeducation, breathing exercises, manual mobilization of the chest, stretching of the shortened muscles (back, lumbar spine, around hip and shoulder), and functional exercises with joint prevention strategies.

Manual mobilization of the chest During expiration, in the supine or sitting position, we asked the patients to place the hands over the ribs and pull the chest diagonally toward $\square$ the 
umbilicus, paying attention to the movements of the ribs. The expiration should not have been with force and the mouth should have been open. We instructed the patients with following words: "Take care to have steady and deep breathing!"

Exercise therapy It could be performed in any position with harmonized movements of the column and the extremities, always working against the deformity and typical AS posture. It was important to avoid abdominal exercises which start with chest elevation, because this would increase kyphosis. These exercises include not only of breathing harmonization but play also an important role in joint mobilization. During the exercises, inspiration was at the starting position, while expiration means the shifting toward the end position. The movements of the column and the chest could be combined with the action of the upper and lower extremities, producing complex exercise. Besides the column's elongation, we focused on tilting of the hip and on the scapula stabilization. The complex exercises, made in a closed kinematic chain, increase muscle elongation.

The full exercise program took $1.5 \mathrm{~h}$ and was performed twice a week for 12 weeks (a total of 24 treatments). During the first 4 weeks, an individualized physical therapy program was conducted, while during the following 8 weeks physical therapy was applied in groups of 2 3 patients.

\section{Clinical assessments}

For the assessment of functional ability and disease activity, the BASFI and BASDAI [17] were recorded. In study II the tests have been completed before and after the 12-week physical therapy program.

Participants were assessed in a clinic-based setting by a trained observer (N.B.). Chest expansion, modified Schober Index, lateral flexion, occiput-to-wall distance, and fingertip-tofloor distance were measured. Each movement had been practiced once before the range of motion was recorded. All baseline and repeat appointments were arranged for the same time. Furthermore, tender points were detected.

\section{Respiratory function tests}

Respiratory function tests typically show mild restrictive respiratory pattern [1]. Spirometry was performed completed before and after the 12-week physical therapy program. Forced vital capacity (FVC), forced expiratory volume during the first second (FEV1), peak expiratory flow (PEF), and maximum voluntary ventilation (MVV) were assessed and 
recorded. The values were expressed as a percentage of the predicted normal values according to the European Respiratory Society criteria [17].

\section{Statistical analysis}

Differences were evaluated by using paired t-test or Wilcoxon signed rank test, depending on the normality of data distribution. The significance level was set at value of $p<0.05$.

\section{Results}

\section{Study I: retrospective analysis of patients with or without biological therapy}

The age, time since diagnosis, and disease activity as well as functional index values of examined AS patients are summarized in Tab. 1.

Differences in disease activity $(42.28 \pm 27.35$ vs. $56.67 \pm 25.99 ; \mathrm{p}=0.019)$ and pain intensity (39.53 \pm 25.76 vs. $51.42 \pm 24.7 ; \mathrm{p}=0.017$ ) between the groups were found. Degree of the occiput-to-wall distance, the posture and spine bendings were better in biological therapy group. Pain and tenderness of the thoracic spine were observed in both groups. The back pain without biologic therapy was slightly higher than other group (Fig. 1).

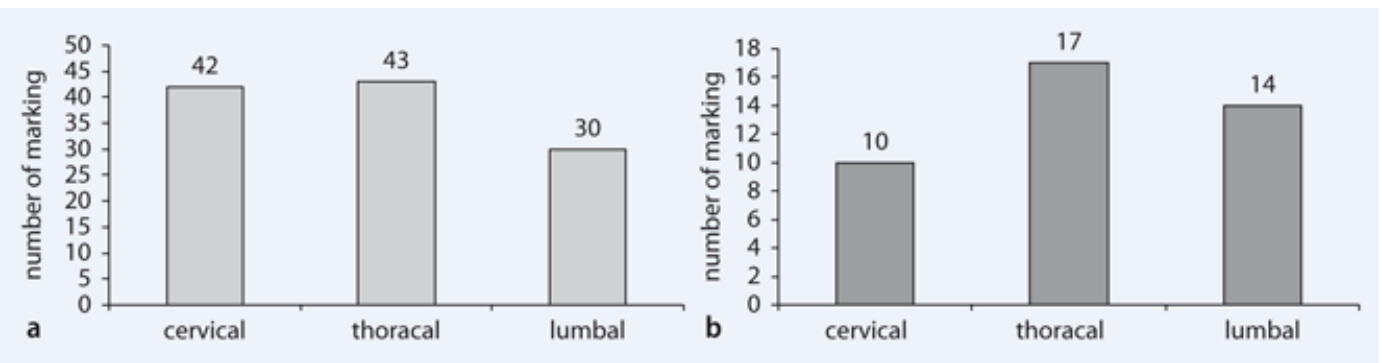

Fig. 1 In study I, position of pain and tenderness in patients a treated with biologicals and $\mathbf{b}$ not treated with biologicals

\section{Study II: prospective analysis of targeted physiotherapy}

In the 10 volunteer AS patients with biological therapy (Tab. 2), assessment of disease activity, and pain intensity significantly improved after the 12-week targeted physiotherapeutic program ( $p=0.002$ and $p<0.001$, respectively; Fig. 2a, b). 

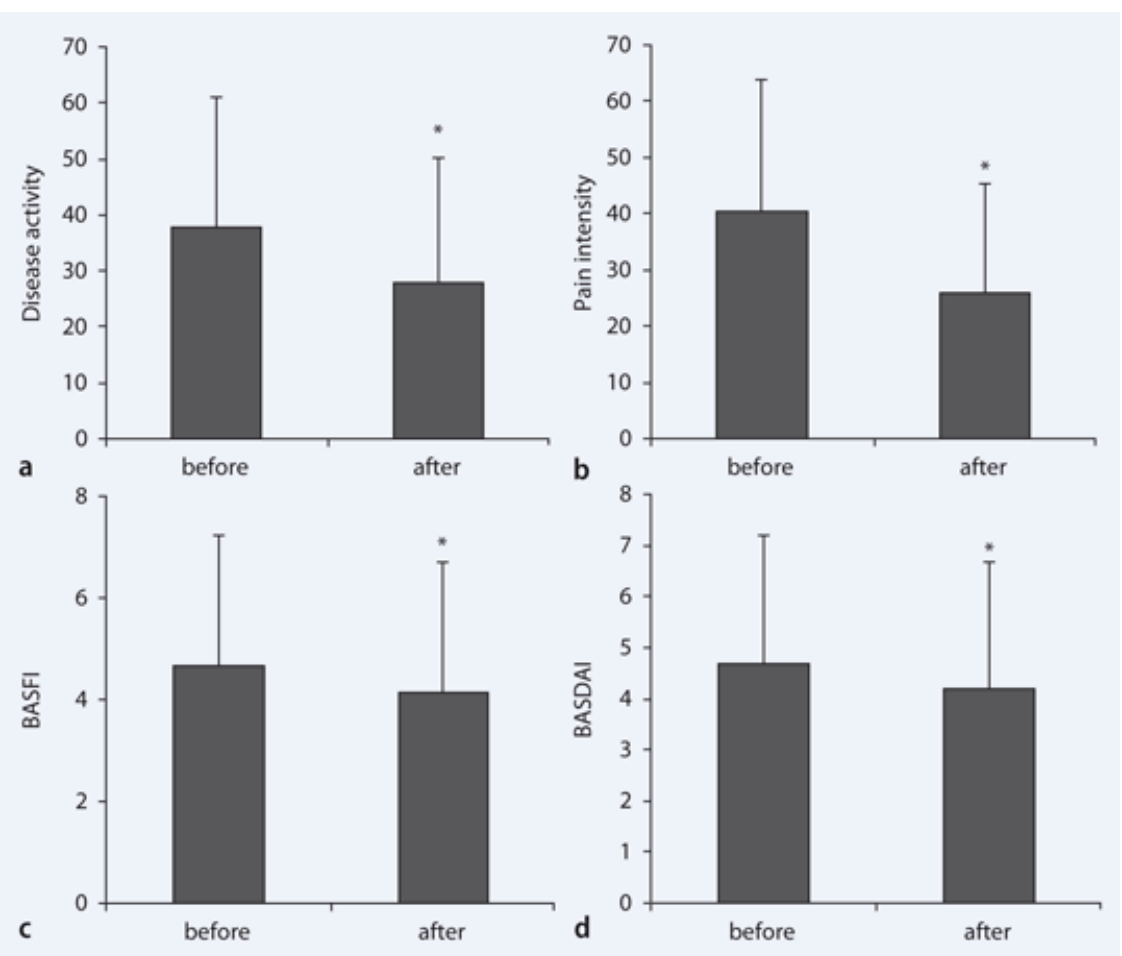

Fig. 2 In study II, the a disease activity, b pain intensity, c Bath Ankylosing Spondylitis Functional Index (BASFI) and $\mathbf{d}$ Bath Ankylosing Spondylitis Disease Activity Index (BASDAl) values before and after physical therapy. Means \pm S.D., $n=10 ;{ }^{*} p<0.05$ vs. before or after

In all cases, improvement in functional parameters and disease activity was observed after the targeted physical therapy program. Both BASFI and BASDAI increased after treatment ( $\mathrm{p}=0.004$ and $\mathrm{p}<0.001$, respectively; Fig. $2 \mathbf{c}, \mathbf{d}$ ). When analyzing the individual changes, almost the same ratio was found when evaluating the "before treatment" versus "after treatment" differences.

Mobility evaluations also revealed significant improvement. Significantly increased finger-to-floor distance $(\mathrm{p}=0,008)$, chest expansion $(\mathrm{p}<0.001)$, and modified Schober Index ( $p=0.031)$ were observed after versus before treatment. The occiput-to wall distance did not change significantly (Fig. 3). Chest expansion exerted a two-fold increase in the majority of patients. The lateral flexion increased significantly in both sides ( $\mathrm{p}=0.002$ right; $\mathrm{p}=0.006$ left), developing symmetrical movements. 

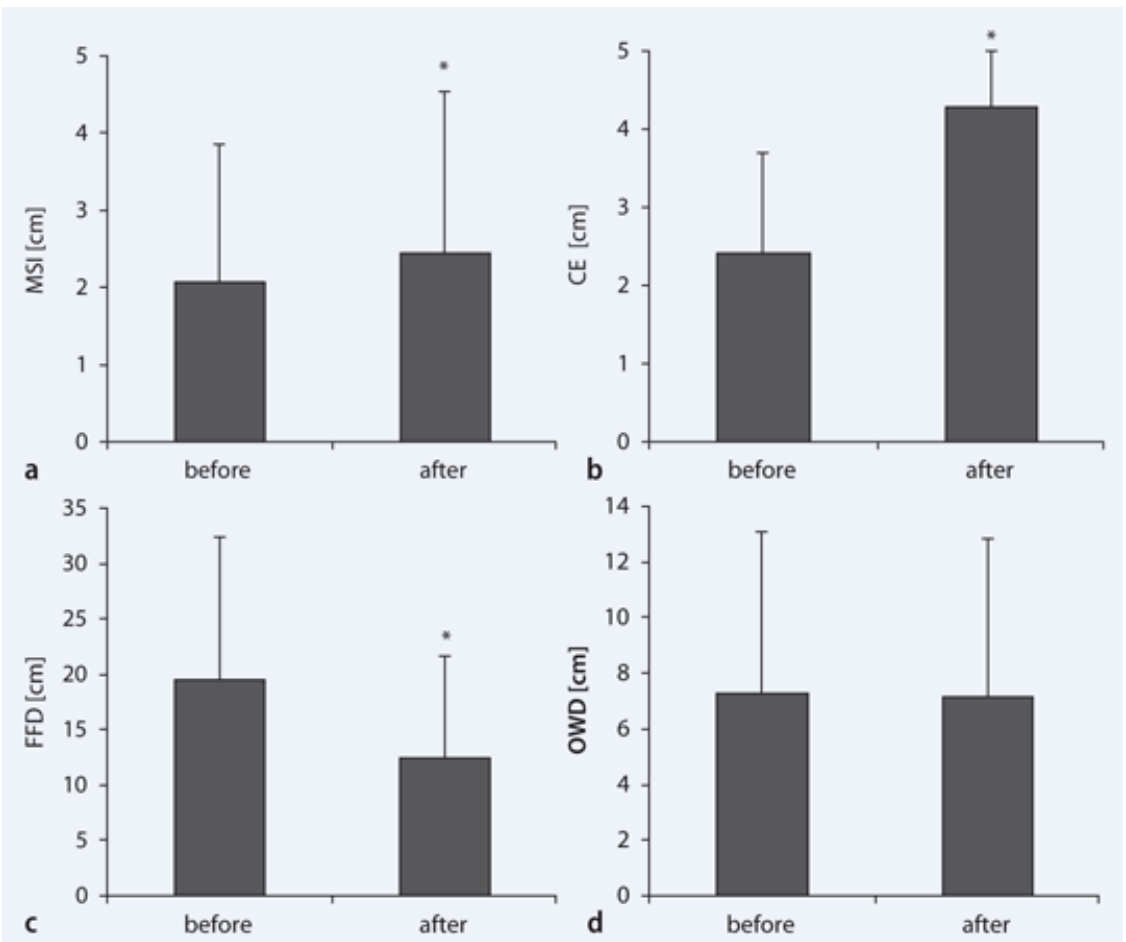

Fig. 3 a Modified Schober Index (MSI), b chest expansion (CE), c finger-to-floor distance (FFD), and d occiput-to-wall distance $(O W D)$ values before and after physical therapy (study II). Means \pm S.D., $n=10 ;{ }^{*} p<0.05$ vs. before or after

Despite the improvement in mobility and functionality, pulmonary function tests including FVC, FEV1, PEF, and MVV showed only non-significant tendencies towards improvement (Fig. 4). There were no obvious individual differences, and the degree of FVC improvement seemed to be independent of the magnitude of chest expansion. 

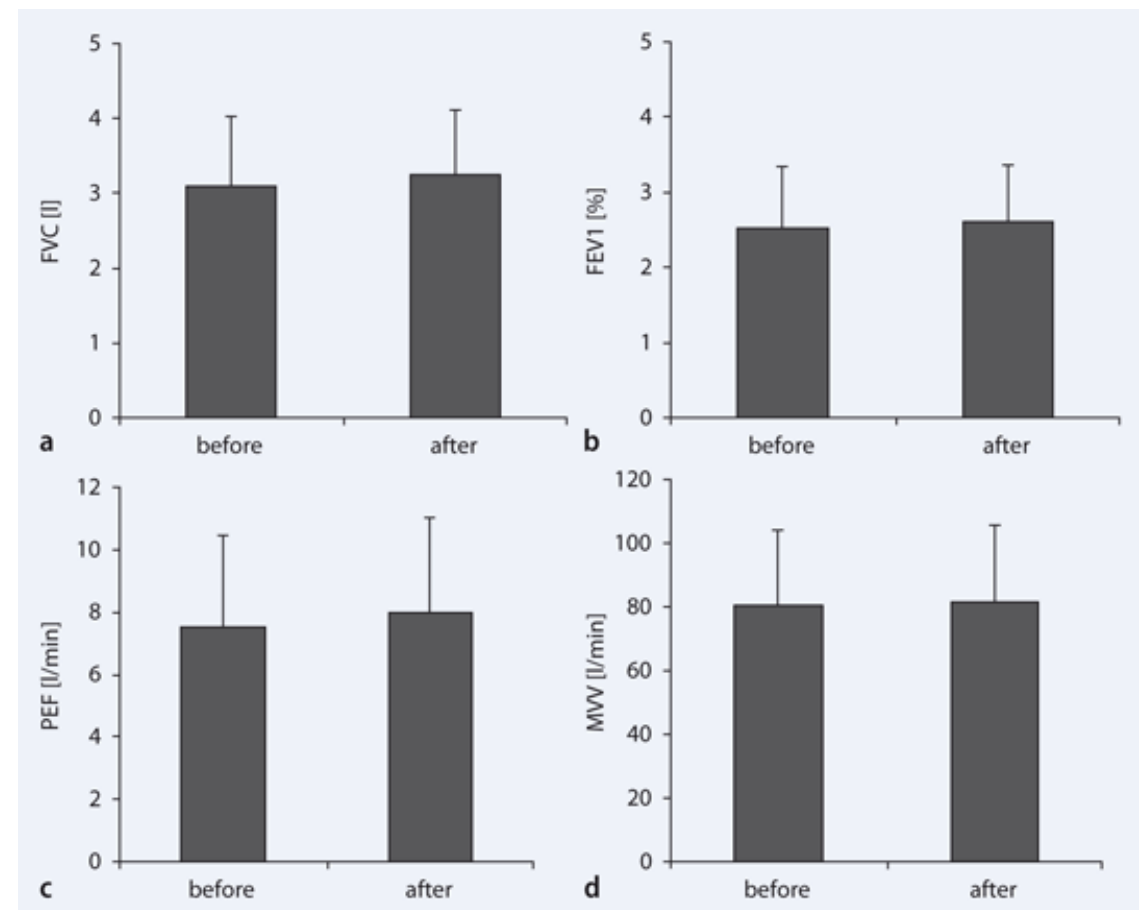

Fig. 4 a Forced vital capacity $(F V C l)$, b 1-s forced expiratory volume (FEV1), c peak expiratory flow $(P E F)$, and $\mathbf{d}$ maximum voluntary ventilation $(M V V)$ values before and after physical therapy (study II). Means \pm S.D., $n=10$

Tenderness of typical tender points of the chest indicated improvement and decreased sensitivity to pressure, mainly over the sternocostal, chondrocostal, manubriosternal junction, and xiphoid process regions. The tenderness of sternocostal and costosternal junctions decreased remarkably, but the sacroiliacal pain did not influence motion. From the characterized tender points, the tenderness of the coracoids process, the superior angle of scapula, the great trochanter, and the ischial tuberosities were marked less after exercise therapy. The tenderness of spinosus processes - which was provoked with palpationdecreased, except for the thoracal region. Pain and stiffness of paravertebral muscles showed improvement with smaller number of markings by the patients (Fig. 5, Fig. 6). 


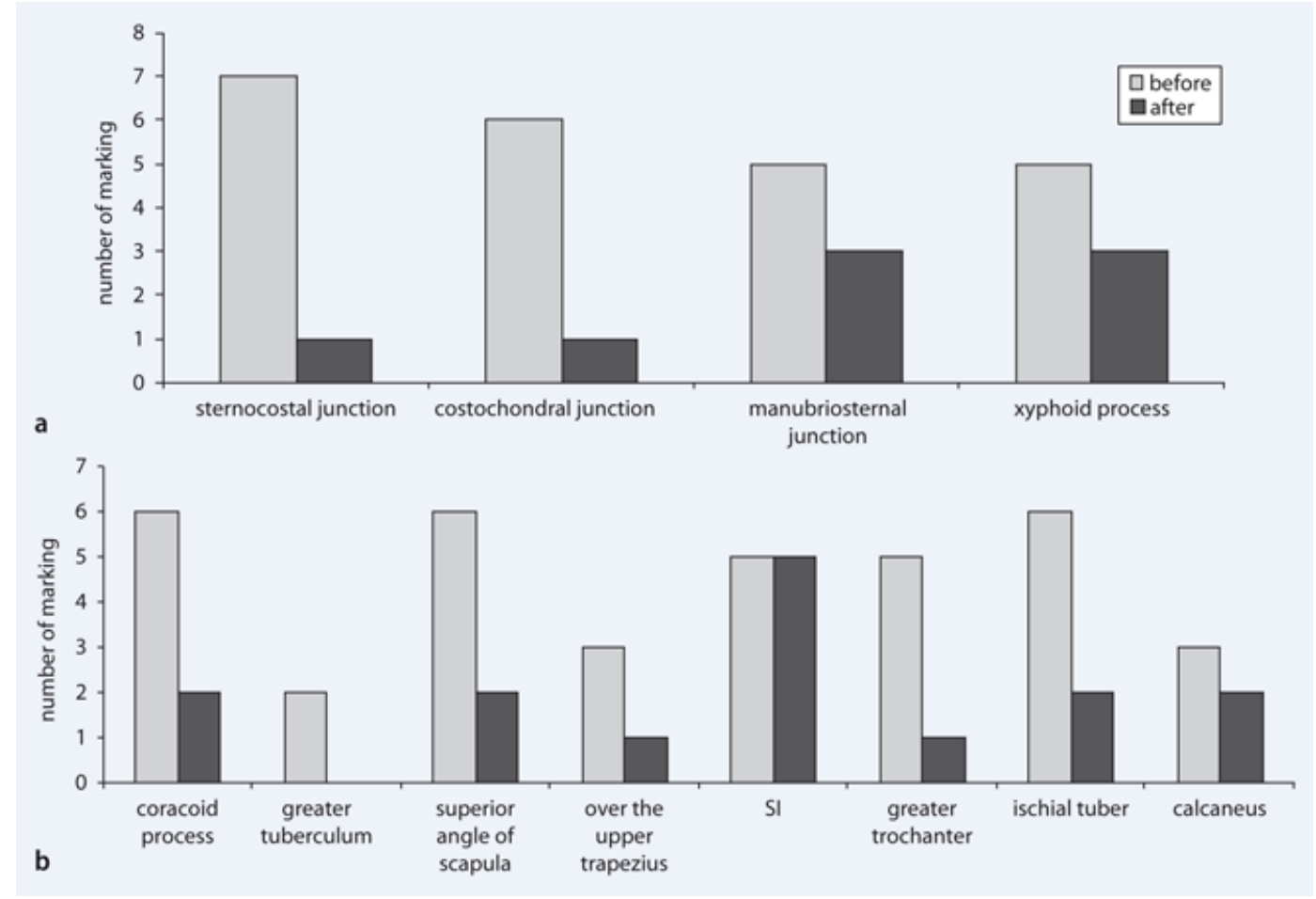

Fig. 5 Number of markings for tenderness of the a chest-fibrocartilagous junctions and $\mathbf{b}$ regional tender points before and after exercise therapy (study II)

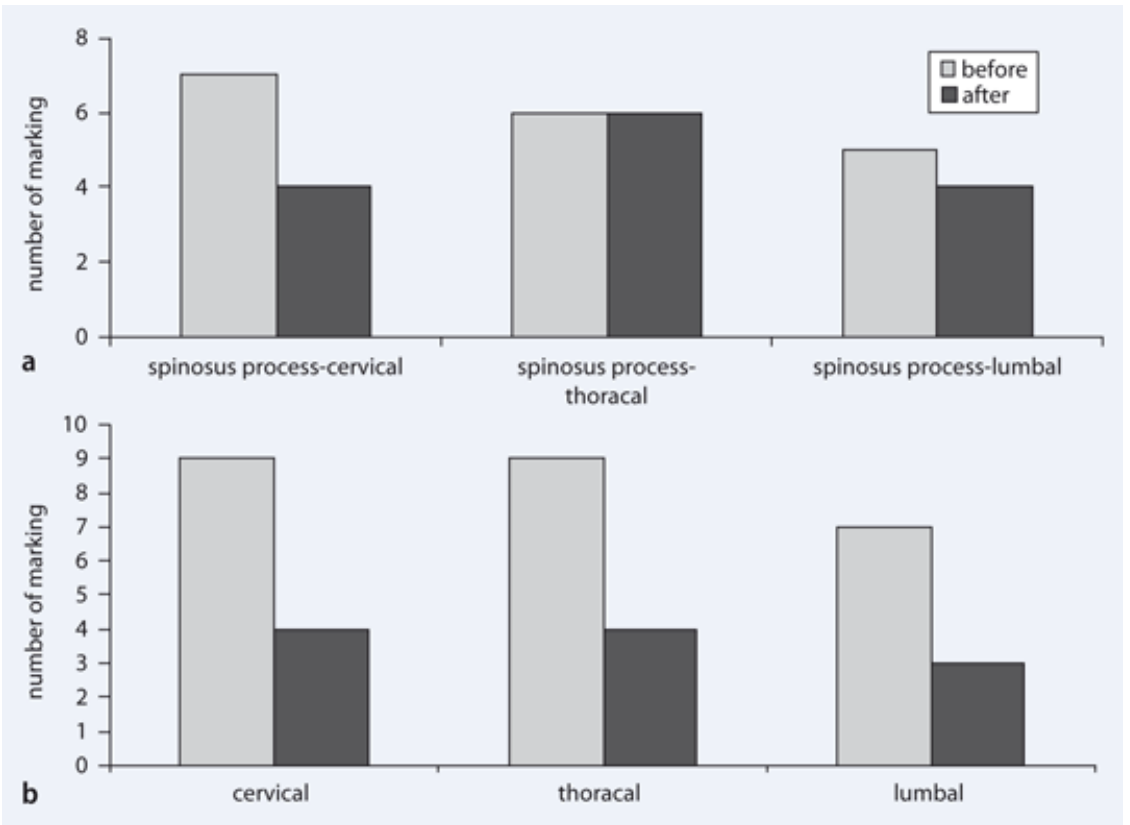

Fig. 6 Number of markings for $\mathbf{a}$ tenderness of spinosus processes and $\mathbf{b}$ stiffness before and after exercise therapy (study II)

\section{Discussion}

In AS, chest pain often occurs as a consequence of costovertebral and costotransverse joint involvement and might be associated with tenderness over sternocostal and costosternal 
junctions $[19,20]$. Pulmonary function abnormalities are due mainly to the restriction of chest wall movement [21]. Restrictive lung disease occurs in kyphoscoliosis and AS due to decreased functional residual capacity, inspiratory capacity, lung compliance, and airway conductance. Some patients reported an inability to expand the chest upon inspiration $[\underline{13}, \underline{21}$, 22]. The normal chest expansion is $5 \mathrm{~cm}$ or greater; however, it is age- and sex-dependent. Limited chest expansion - in individual insidious onset of chronic low back pain and without chest disease such as emphysema or scoliosis — should strongly raise the possibility of AS [ㅈ]

Patients in whom disease activity cannot be adequately controlled by conventional techniques may be treated with biological agents targeting TNF- $\alpha$, which are now licensed for treatment of patients with severe AS whose symptoms do not respond adequately to conventional therapy. Without treatment the spine increasingly stiffens and the peripherial (mostly large) joints are often destroyed by inflammatory processes. Early diagnosis is of utmost importance because today treatment with novel drugs is feasible with TNF- $\alpha$ inhibitors being particularly effective during the early stages of the disease.

Demonstrated by our patients' parameters, the inhibition of inflammation led to lower pain intensity and disease activity, better physical conditions and functionality. In the case of 55 patients, moderate pain, larger MSI and chest expansion were observed, showing decreased BASFI and BASDAI values $[\underline{23}, \underline{24}, \underline{25}, \underline{26}, \underline{27}]$. The limitation of this study part is its retrospective character.

Physical therapy applied individually or in groups has general and specific beneficial effects for patients suffering from AS $[\underline{28}, \underline{29}, \underline{30}]$. Several studies reported improvement in the wall-to-occiput distance, finger-to-floor distance, chest expansion, Schober Index, and pulmonary function after a couple of weeks of intensive physiotherapy $[\underline{1}, \underline{14}, \underline{31}, \underline{32}]$.

In study II, which was a prospective but nonrandomized self-controlled study, we investigated functional and physical parameters with respect to the above mentioned structural-functional changes in AS patients currently receiving anti-TNF therapy. Results suggested significant improvements in function and mobility.

Our physical exercise program included elements of conventional and breathing exercises as well as global posture reeducation. The stretching theories also played an important role, adapted for the alterations in the column and the chest. The conventional exercises focus on mobilization of the great joints and on strengthening of the shoulder and hip complex muscles. The aim of the breathing exercises is mobilization of the joints in the spinal column 
and chest, together with development of appropriate breathing mechanics, while the basics of global posture reeducation are spine elongation and hip complex position according to biomechanical analyses $[\underline{1}, \underline{8}, \underline{12}, \underline{13}, \underline{17}]$.

We observed improvements in finger-to-floor distance and thoracolumbar lateral flexion, slightly in modified Schober Index, while the occiput-to-wall distance did not change markedly. The finger-to-floor distance depends on the extensibility of hamstring muscles and the thoracolumbar lateral flexion is influenced by the extensibility of spine muscles. The occiput-to-wall distance is defined by curvature and mobility of the spine, tilt of the pelvis, and stiffness around the hip and spine [20, 33]. Normal chest expansion requires normal costovertebral, costosternal, manubriosternal, and sternoclavicular joints. If any of these joints are involved, chest expansion is diminished $[\underline{7}, \underline{10}, \underline{19}]$. Our results also showed associations of pain, numbers of tender points, chest expansion, and thoracolumbar lateral flexion.

Durmuş et al. [34] compared the effects of conventional exercise and global posture reeducation (GPR). There were significant improvements for BASDAI and BASFI scores in all groups, significant improvements in the VAS pain, chest expansion, but the GPR method resulted in greater improvements than the conventional exercise program in specific pulmonary function parameters like forced vital capacity, forced expiratory volume in $1 \mathrm{~s}$, and peak expiratory flow parameters.

Previously, the pulmonary function tests of our patients had shown that the typical pattern was restrictive, characterized by low chest expansion and lateral flexion. The restrictive pattern characterized by low FVC is frequently associated with a decreased thoracic expansion [ $7, \underline{10}]$. After 12 weeks of targeted physical therapy, respiratory function improved slightly, but not significantly — probably because this program did not contain direct cardiopulmonary exercises. Physical therapy included manual mobilization and breathing exercise, and so these techniques could not ameliorate breathing muscle endurance. The muscles' endurance and response to differenct exercises decrease in AS, which correlated significantly with age, disease duration, chest expansion, modified Shober Index, and vital capacity $[\underline{35}, \underline{36}, \underline{37}]$.

Karapolat et al. [38] found that swimming, walking, and conventional exercise (CE) had beneficial effects on quality of life and pulmonary function. Aerobic exercises such as swimming and walking in addition to CE significantly increased functional capacities of 
patients. However, no significant differences were detected in the exercise groups with regard to BASDAI and BASFI.

Koseoglu et al. [22] also reported that the exercise training improves some of the spinal and respiratory limitation in AS; however, exercise training, as part of pulmonary rehabilitation, was not sufficient evidence for effectiveness. Comparing with the values recorded at the beginning of the study, they observed slight increases in FVC, FEV1, and MVM. Our results correspond nicely with these observations; however, they also found a significant correlation between FVC, chest expansion, and lumbar flexion.

Ortancil et al. [39] applied a 6-week home-based program, using breathing and upper extremity exercises. In their study, chest expansion, pulmonary function, and BASFI scores significantly improved. In our study, significant improvement of BASFI and BASDAI scores were also found. Sahin et al. [21] suggested a significant negative correlation between functionality and pulmonary muscle strength, but they did not find a significant relation between BASFI and chest expansion.

Enthesitis is inflammation at the insertion point of ligaments, tendons, joint capsule, or fascia to bone, and a well-known characteristic of AS. Entheseal pain may be mild, moderate, severe, or disabling and, there is a correlation with disease activity, tenderness, and number of tender points $[\underline{40}, \underline{41}]$.

Back pain and stiffness were dominant in these 75 AS patients. Lower back pain is dependent on inflammatory activity of sacroiliac joints; in particular ankylosis correlates with limited range of motion (ROM), paravertebral stiffness, and the inflammation at the intervertebral, costovertebral, costotransversal joints and fibrocartilagous junctions, which increase pain.

As the result of targeted exercise therapy (in study II), the tenderness of cervical and thoracic spinosus processes decreased, but was stagnant in the thoracic region, whereas motion did not influence the inflammatory process and ragiological conditions [42]. The degree of pain and tenderness correlate with patient assessment of disease activity. The paravertebral region was activated by exercises; therefore, muscles pain and stiffness decreased. Exercise with stretching resulted in favorable structural transformation in muscles (the number of sarcomers increased) and pain decreased [43, 44]. The tenderness of fibrocartilagous junctions showed the greatest improvement. 
Beside targeted physiotherapy which includes adapted exercise therapy, biological agents are highly effective in the therapy of AS. Because of the locomotor manifestations of the disease, stimulation of motion is indispensable in therapy, which can improve mobility and function, supplementing the targeted therapy.

The results of our and previous studies showed that AS patients receiving biological therapy and additional physiotherapy may show remarkable improvement. We suggest that physical therapy has an important and additive role in the complex therapy of AS. For this purpose, a targeted exercise program may contribute to joint protection strategies and pharmacological treatment.

The ratio of the volunteers ( 17 of 55 patients, 30.9\%; those who completed the program 10 of 55 patients, $18.18 \%$ ) was very low in our study. This may indicate low motivation of patients for physical activity and exercises in addition to logistic reasons. According to these preliminary results, we are encouraged to continue the studies with this physical exercise combination and increasing the case number for new studies.

\section{Conclusion}

Physical therapy may be of important additive value in AS patients being treated with biologicals. Our exercise program improved functional parameters as well as spine and chest mobility, thus, enhancing the positive effects of biological therapy.

Key messages are

- complex physiotherapy, in addition to biologics, may improve ankylosing spondylitis,

- a targeted physiotherapy program improved pain intensity, and

- physiotherapy improved chest mobility and respiratory function.

Conflict of interest No statement made.

\section{References}

1. Fisher LR, Cawley MI, Holgate ST (1990) Relationship between chest expansion, pulmonary function and exercise tolerance with AS. Ann Rheum Dis 49:921-925 
2. Franssen MJ, Herwaarden CL van, Putte LB van de, Gribnau FW (1986) Lung function in patients with ankylosing spondylitis. A study of the influence of disease activity and treatment with nonsteroidal antiinflammatory drugs. J Rheumatol 13:936-940

3. Haslock I (1993) Ankylosing spondylitis. Baillieres Clin Rheumatol 7:99-115

4. Sengupta R, Stone MA (2007) The assessment of ankylosing spondylitis in clinical practice. Nat Clin Pract Rheumatol 3:496-503

5. Dalyan M, Guner A, Tuncer S et al (1999) Disability in ankylosing spondylitis. Disabil Rehabil 21:74-79

6. Dawes PT, Sheeran TP, Hothersall TE (1988) Chest pain-common feature of ankylosing spondylitis. Postgrad Med J 64:27-29

7. Kanathur N, Lee-Chiong T (2010) Pulmonary manifestations of ankylosing spondylitis. Clin Chest Med 31:547-554

8. Moll JM, Wright V (1973) The pattern of chest and spinal mobility in ankylosing spondylitis. Rheumatol Rehabil 12:115-134

9. Falkenbach A, Curda B (2001) Symptoms, effects on quality of life, judgment and expectations of treatment in active ankylosing spondylitis: the patient's view. Rehabilitation (Stuttg) 40:275-279 (in German)

10. Feltelius N, Hedenstrom H, Hillerdal G, Hallgren R (1986) Pulmonary involvement in ankylosing spondylitis. Ann Rheum Dis 45:736-740

11. De Keyser F, Van den Bosch F, Mielants H (2006) Anti-TNF-alpha therapy in ankylosing spondylitis. Cytokine 33:294-298

12. Smidt N, Vet HC de, Bouter LM et al (2005) Effectiveness of exercise therapy: a bestevidence summary of systematic reviews. Aust J Physiother 51:71-85

13. Linden S van der (2002) Physiotherapy in ankylosing spondylitis: what is the evidence? Clin Exp Rheumatol 20:S60-S64

14. Viitanen JV (1992) Effect of physiotherapy on spinal mobility in AS. Scand J Rheumatol $21: 38-41$

15. Gyurcsik ZN, András A, Bodnár N et al (2012) Improvement in pain intensity, spine stiffness, and mobility during a controlled individualized physiotherapy program in ankylosing spondylitis. Rheumatol Int 32:3931-3936

16. Goie The HS, Steven MM, Linden SM van der, Cats A (1985) Evaluation of diagnostic criteria for ankylosing spondylitis: a comparison of the Rome, New York and modified 
New York criteria in patients with a positive clinical history screening test for ankylosing spondylitis. Br J Rheumatol 24:242-249

17. Heikkila S, Viitanen JV, Kautiainen H, Kauppi M (2000) Sensitivity to change of mobility tests; effect of short term intensive physiotherapy and exercise on spinal, hip, and shoulder measurements in spondyloarthropathy. J Rheumatol 27:1251-1256

18. American Thoracic Society/European Respiratory Society (2002) ATS/ERS Statement on respiratory muscle testing. Am J Respir Crit Care Med 166:518-624

19. Chandran V, O'Shea FD, Schentag CT et al (2007) Relationship between spinal mobility and radiographic damage in ankylosing spondylitis and sporiatric spondylitis: a comparative analysis. J Rheumatol 34:2463-2465

20. Gran JT, Husby G, Hordvik M et al (1984) Radiological changes in men and women with ankylosing spondylitis. Ann Rheum Dis 43:570-575

21. Sahin G, Calikoglu M, Ozge C et al (2004) Respiratory muscles strength but not BASFI score relates to diminished chest expansion in ankylosing spondylitis. Clin Rheumatol 23:199-202

22. Koseoglu F, Ozel S, Demirdeviren S et al (1998) Effects of a pulmonary rehabilitation program on pulmonary functions, cycle ergometry test-parameters, exercise tolerance, and spinal mobility in patients with ankylosing spondylitis. Eur J Phys Med Rehabil $8: 67-70$

23. Freeston J, Barkham N, Hensor E et al (2007) Ankylosing spondylitis, HLA-B27 positivity and the need for biologic therapies. Joint Bone Spine 74:140-143

24. Baralikos X, Listing J, Brandt J et al (2007) Radiographic progression in patients with ankylosing spondylitis after 4yrs of treatment with the anti-TNF- $\alpha$ antibody infliximab. Rheumatology (Oxford) 46:1450-1453

25. Dougados M, Braun J, Szanto S et al (2011) Efficacy of etanercept on rheumatic signs and pulmonary function tests in advanced ankylosing spondylitis: results of a randomised double-blind placebo-controlled study (SPINE). Ann Rheum Dis 70:799-804

26. Brandt J, Khariouzov A, Listing J et al (2003) Six-month results of a double-blind, placebo-controlled trial of etanercept treatment in patients with active ankylosing spondylitis. Arthritis Rheum 48:1667-1675 
27. Davis JC Jr, Van Der Heijde D, Braun J et al (2003) Recombinant human tumor necrosis factor receptor (etanercept) for treating ankylosing spondylitis: a randomized, controlled trial. Arthritis Rheum 48:3230-3236

28. Elliott CG, Hill TR, Adams TE et al (1985) Exercise performance of subjects with ankylosing spondylitis and limited chest expansion. Bull Eur Physiopathol Respir $21: 363-368$

29. Ince G, Sarpel T, Durgun B, Erdogan S (2006) Effects of a multimodal exercise program for people with ankylosing spondylitis. Phys Ther 86:924-935

30. Viitanen JV, Kautiainen H, Kokko ML, Ala-Peijari S (1995) Age and spinal mobility in ankylosing spondylitis. Scand J Rheumatol 24:314-315

31. Mengshoel AM, Robinson HS (2008) Clinical significance of spinal mobilization for patient with ankylosing spondylitis evaluated by quantitative assessment and patient interviews. Disabil Rehabil 30:355-364

32. Viitanen JV, Lehtinen K, Suni J, Kautiainen H (1995) Fifteen months' follow-up of intensive inpatient physiotherapy and exercise in ankylosing spondylitis. Clin Rheumatol $14: 413-419$

33. Viitanen JV, Heikkilä S, Kokko ML, Kautiainen H (2000) Clinical assessment of spinal mobility measurements in ankylosing spondylitis: a compact set for follow-up and trials? Clin Rheumatol 19:131-137

34. Durmuş D, Alayli G, Uzun O et al (2009) Effects of two exercise interventions on pulmonary functions in the patients with ankylosing spondylitis. Joint Bone Spine $76: 150-155$

35. Halvorsen S, Vøllestad NK, Fongen C et al (2012) Physical fitness in patients with ankylosing spondylitis: comparison with population controls. Phys Ther 92:298-309

36. Feltelius N, Hedenstrom H, Hillerdal G, Hallgren R (1986) Pulmonary involvement in ankylosisng spondylitis. Ann Rheum Dis 45:736-740

37. Ozdem Yr O, Inanici F, Hasçelik Z (2011) Reduced vital capacity leads to exercise intolerance in patients with ankylosing spondylitis. Eur J Phys Rehabil Med 47:391-397

38. Karapolat H, Eyigor S, Zoghi M et al (2009) Are swimming or aerobic exercise better than conventional exercise in ankylosing spondylitis patients? A randomised controlled study. Eur J Phys Rehabil Med 45:449-457 
39. Ortancil O, Sarikaya S, Sapmaz P et al (2009) The effect(s) of a six-week homebased exercise program on the respiratory muscle and functional status in ankylosing spondylitis. J Clin Rheumatol 15:68-70

40. Kaya A, Ozgocmen S, Kamanli A et al (2007) Evaluation of a quantitative scoring of enthesitis in ankylosing spondylitis. J Clin Rheumatol 13:303-306

41. D’Agostino MA, Olivieri I (2006) Enthesitis. Best Pract Res Clin Rheumatol 20:473486

42. Pascual E, Castellano JA, López E (1992) Costovertebral joint changes in ankylosing spondylitis with thoracic pain. Br J Rheumatol 31:413-415

43. Paalanne N, Korpelainen R, Taimela $\mathrm{S}$ et al (2008) Isometric trunk muscle strength and body sway in relation to low back pain in young adults. Spine 33:435-441

44. Bulstrode SJ, Barefoot J, Harrison RA, Clarke AK (1987) The role of passive stretching in the treatment of ankylosing spondylitis. Br J Rheumatol 26:40-42 
Tab. 1 Patients' data in study I with or without biological therapy

\begin{tabular}{|c|c|c|}
\hline \multirow[t]{2}{*}{ Parameters } & \multicolumn{2}{|l|}{ Groups } \\
\hline & With biological therapy $(n=55)$ & Without biological therapy $(n=20)$ \\
\hline Age (years) & $44.23 \pm 10.59$ & $46.35 \pm 10.2$ \\
\hline Disease duration since diagnosis (years) & $14.4 \pm 10.56$ & $16.15 \pm 10.75$ \\
\hline Degree of sacroiliitis & $3.3 \pm 0.89$ & $2.89 \pm 1.13$ \\
\hline Disease activity (cm on VAS) & $42.28 \pm 27.35$ & $56.67 \pm 25.99^{*}$ \\
\hline Pain intensity (cm on VAS) & $39.53 \pm 25.76$ & $51.42 \pm 24.7^{*}$ \\
\hline BASFI (cm on VAS) & $4.49 \pm 2.87$ & $4.89 \pm 2.95$ \\
\hline BASDAI (cm on VAS) & $3.63 \pm 2.46$ & $4.58 \pm 2.29$ \\
\hline Modified Schober Index $(\mathrm{cm})$ & $2.64 \pm 1.93$ & $2.18 \pm 2.01$ \\
\hline Occiput-to-wall distance $(\mathrm{cm})$ & $6.6 \pm 8.14$ & $9.83 \pm 9.06$ \\
\hline Chest expansion $(\mathrm{cm})$ & $2.8 \pm 1.29$ & $2.45 \pm 1.22$ \\
\hline
\end{tabular}

Mean \pm S.D., ${ }^{*}<<0.05$ vs. group with biological therapy.VAS visual analog scale, BASFI Bath Ankylosing Spondylitis Functional Index, BASDA/ Bath Ankylosing Spondylitis Disease Activity Index. 
Tab. 2 Summary of patients' data taking part in study II

\begin{tabular}{|l|l|}
\hline Age (years) & $52.4 \pm 13.64$ \\
\hline Height (cm) & $167 \pm 12.79$ \\
\hline Weight (kg) & $76.2 \pm 15.5$ \\
\hline Disease duration (years) & $16.1 \pm 13$ \\
\hline Sl average stage & $3.4 \pm 0.8$ \\
\hline Biologic therapy duration (years) & $1.8 \pm 0.75$ \\
\hline
\end{tabular}

Means \pm S.D., $n=10$ 